\title{
Highly Fluorescent Macrophages in Colonic Mucosa Under Autofluorescence Imaging Endoscopy: A Brief Case Report
}

\author{
Tetsuro Takamatsu et al.* \\ Department of Pathology and Cell Regulation, Kyoto Prefectural University of Medicine \\ Graduate School of Medical Science, \\ Japan
}

\section{Introduction}

Autofluorescence imaging (AFI) endoscopy for detection of early neoplastic lesions has recently received considerable attention in the field of clinical gastroenterology (van den Broek et al., 2008; Matsuda et al., 2008; Inoue et al., 2010). The main source of autofluorescence eruption under blue light excitation has been considered to be submucosal collagen, not the mucosal layer in human (Izuishi et al., 1999; Huang et al., 2004). In this report, we describe a rare case in which highly fluorescent mucosal macrophages made a superficial-type colonic adenoma remarkably easy to detect. To the best of our knowledge, there has been no case report documenting that the mucosal macrophages are the main contributors to colonic autofluorescence detected at autofluorescence colonoscopy.

\section{Brief case report}

A 74-year-old man with chronic renal failure was referred to our department in July 2006 for evaluation of positive fecal occult blood test. He had been receiving long-term hemodialysis since 1997. White light (WL) colonoscopic examination revealed a superficial-type neoplastic lesion in the descending colon (Fig. 1A). An inspection with AFI (CF-FH260AZI, Olympus Medical Systems Corp., Tokyo, Japan) (excitation: 390-470 nm; emission: 500-630 nm; green reflection: 540-560 nm) showed remarkably strong autofluorescence signal in normal colonic lumen (Fig. 1B). Unusual cobblestone appearance of the strong autofluorescence signal in the non-neoplastic lesion around the neoplasia was observed. Submucosal vessels commonly seen under AFI examination were not apparent (See Fig. 1C for comparison.).

\footnotetext{
* Yoshinori Harada' ${ }^{1}$ Naoki Wakabayashi², Katsuichi Imaizumi1 ${ }^{1}$, Kiichiro Miyawaki ${ }^{1,2}$, Keimei Nakano ${ }^{1,2}$, Yoshihisa Yamaoka ${ }^{1}$, Akio Yanagisawa ${ }^{3}$ and Toshikazu Yoshikawa ${ }^{2}$

1 Department of Pathology and Cell Regulation, Kyoto Prefectural University of Medicine Graduate School of Medical Science, Japan,

2 Department of Molecular Gastroenterology and Hepatology, Kyoto Prefectural University of Medicine Graduate School of Medical Science, Japan,

3 Department of Surgical Pathology, Kyoto Prefectural University of Medicine Graduate School of Medical Science, Japan.
} 
Since the autofluorescence intensity of the neoplastic lesion was reduced, the superficialtype neoplasia was clearly recognized. On hematoxylin and eosin (H\&E) staining, the nonneoplastic lesion showed slight nonspecific colitis with epithelial hyperplasia (Fig. 2D) and findings for the neoplastic lesions were consistent with tubular adenoma with high-grade dysplasia (Fig. 1D). No sign of collagenous colitis, amyloidosis, or melanosis coli was found.
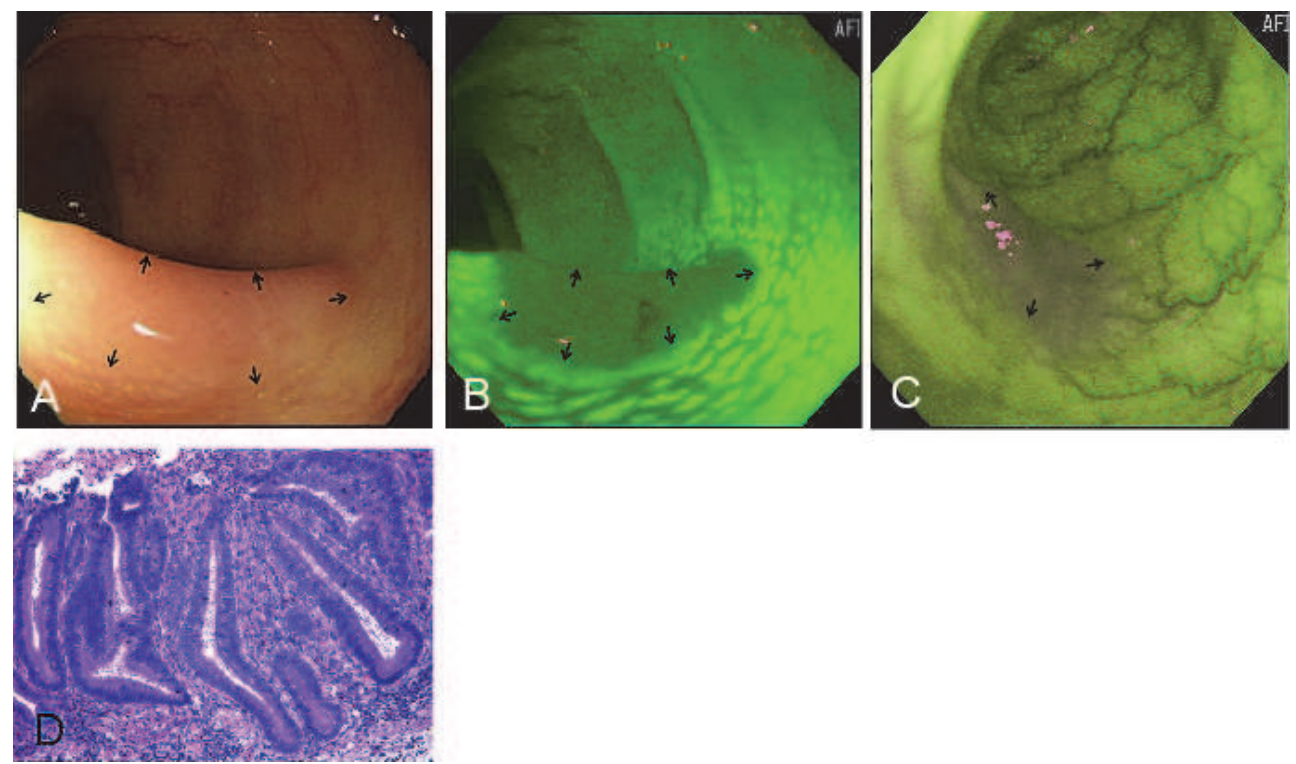

Fig. 1. A, A WL image of the colonic mucosa and the superficial-type colonic tumor (arrows). B, An AFI image of the surrounding mucosa with strong autofluorescence signal and the tumor with reduced autofluorescence signal (arrows). Uncommon cobblestone appearance of the intense autofluorescence signal in the non-neoplastic lesion clearly reveals the tumor. C, An AFI image in a classic case of superficial-type colonic tumor (arrows), shown for comparison. Note that cobblestone appearance of the autofluorescence signal is not apparent and submucosal vessels are clearly visible in non-neoplastic lesion. D, H\&Estaining of the superficial-type colonic tumor for this patient.

Stereomicroscopic images for a mucosal cross-section of a biopsied non-neoplastic colonic specimen showed intense autofluorescence signals with granular pattern (arrowheads in Fig. 2A) on the luminal zone of the mucosal layer (upper left panel of Fig. 2A, WL image; upper right panel, autofluorescence image: excitation: $436 \mathrm{~nm}$; emission $>455 \mathrm{~nm}$; lower left panel, autofluorescence image: excitation: $405 \mathrm{~nm}$; emission > $430 \mathrm{~nm}$; lower right panel, autofluorescence image: excitation: $365 \mathrm{~nm}$; emission > $400 \mathrm{~nm}$ ). Immunohistochemical investigation of the non-neoplastic mucosa showed that cells containing the granular autofluorescence signals were positive for CD68, a marker for macrophages (Fig. 2B and 2C). Normalized fluorescence spectra of colonic mucosal cross-sections for this patient and in a classic case are shown (Fig. 3, 4, and 5). The emission peaks of the spectra with excitation at 436 $\mathrm{nm}, 405 \mathrm{~nm}$ and $365 \mathrm{~nm}$ for our patient were around $480 \mathrm{~nm}$ (Fig. 3A, 4A, and 5A). 

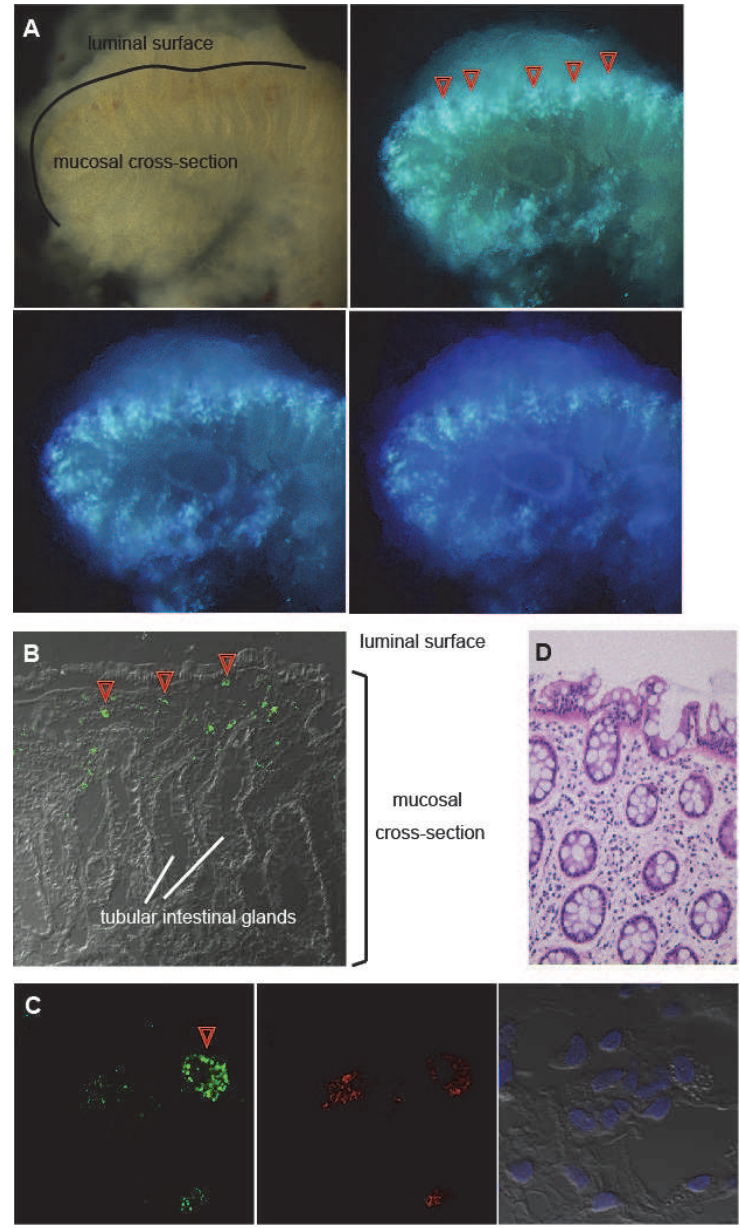

Fig. 2. Evaluation of the source of autofluorescence eruption in the non-neoplastic mucosa.

A, Stereomicroscopic image of a biopsied colonic specimen (upper left panel, WL image; upper right panel, autofluorescence image: excitation: 436 nm [D436/10x; Chroma Technology Corp., Rockingham, VT]; emission: > 455 nm [E455LP v2; Chroma Technology Corp.]; lower left panel, autofluorescence image: excitation: 405 nm [D405/20x; Chroma Technology Corp.]; emission: > $430 \mathrm{~nm}$ [HQ430LP; Chroma Technology Corp.]; lower right panel, autofluorescence image: excitation: $365 \mathrm{~nm}$ [D365/10x; Chroma Technology Corp.]; emission: $>400 \mathrm{~nm}$ [E400LP v2; Chroma Technology Corp.]). Strong autofluorescence signals (arrowheads) with granular pattern are observed in the luminal zone of the mucosal layer. B, A low-magnification confocal image of autofluorescence (arrowheads) (excitation: $440 \mathrm{~nm}$; emission: 450-510 $\mathrm{nm}$ ) obtained with differential interference contrast (DIC) imaging in a 6- $\mu \mathrm{m}$ thin-sliced section. C, High-magnification confocal images of autofluorescence (left panel) (arrowhead) (excitation: $440 \mathrm{~nm}$; emission: 450-510 nm) and CD68 immunostaining (middle panel) in a thin-sliced section. Nuclei were detected with TO-PRO3 iodide (blue) (right panel). D, Histological appearance of H\&E-stained tissue sections of the non-neoplastic mucosa. 
A

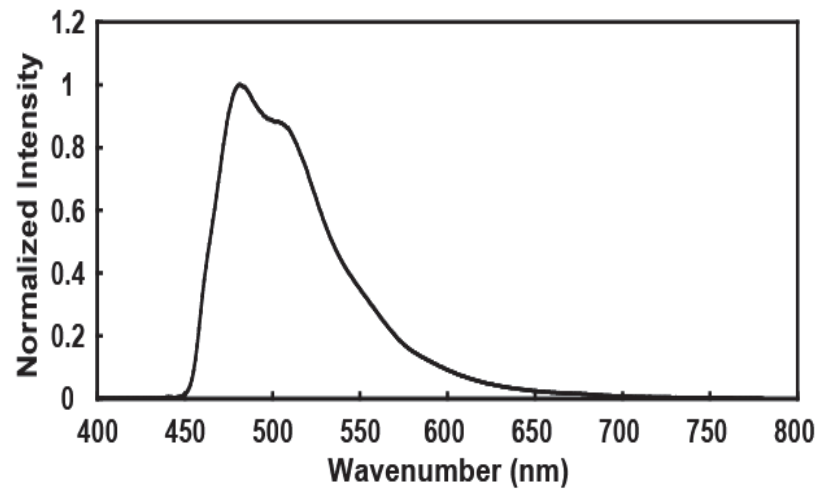

B

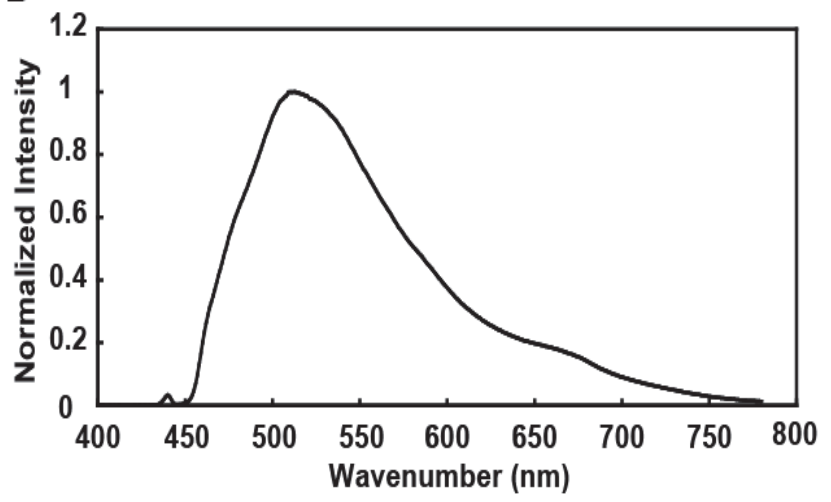

Fig. 3. Comparison of fluorescence spectra with excitation at $436 \mathrm{~nm}$. A, A normalized fluorescence spectrum of a colonic mucosal cross-section for this patient. B, A normalized fluorescence spectrum of a colonic mucosal cross-section in a classic case, shown for comparison. The fluorescence spectra (>455 nm) (E455LP v2; Chroma Technology Corp.) excited at $436 \mathrm{~nm}$ (D436/10x; Chroma Technology Corp.) were analyzed by using a multichannel spectrophotometer (MCPD-7000; Otsuka Electronics, Osaka, Japan). 


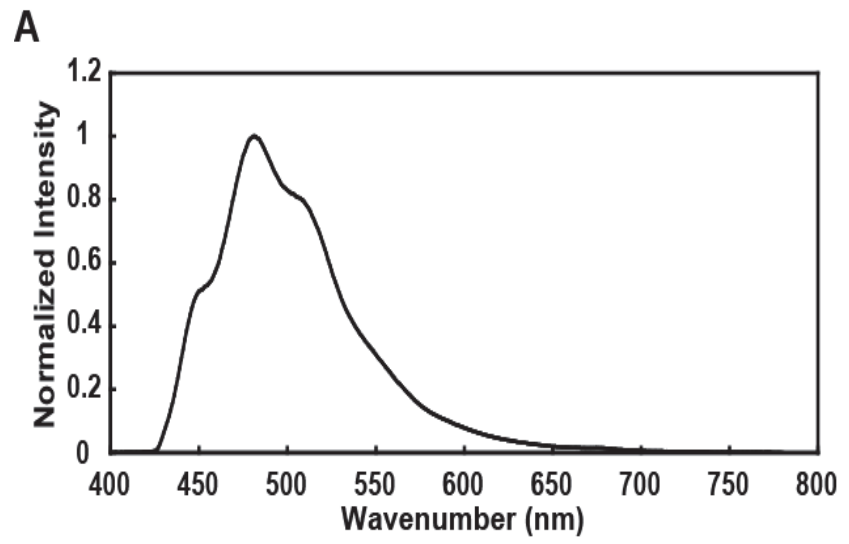

B

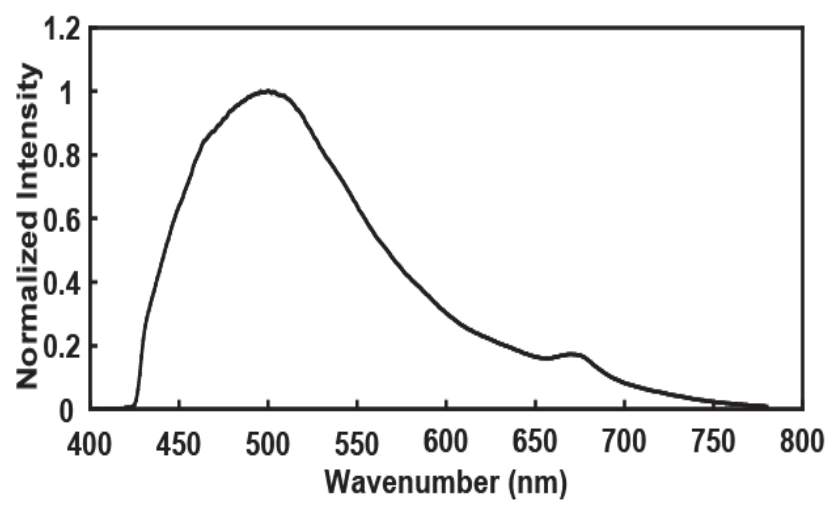

Fig. 4. Comparison of fluorescence spectra with excitation at $405 \mathrm{~nm}$. A, A normalized fluorescence spectrum of a colonic mucosal cross-section for this patient. B, A normalized fluorescence spectrum of a colonic mucosal cross-section in a classic case, shown for comparison. The fluorescence spectra (>430 nm) (HQ430LP; Chroma Technology Corp.) excited at $405 \mathrm{~nm}$ (D405/20x; Chroma Technology Corp.) were analyzed by using the multichannel spectrophotometer. 
A

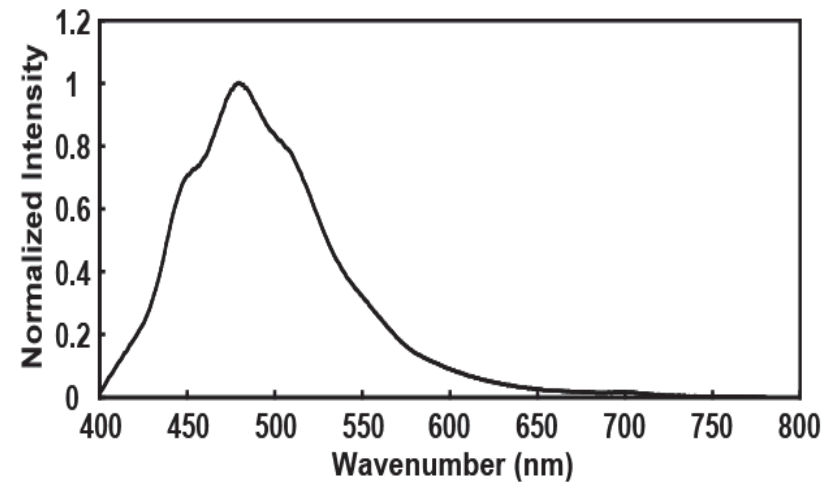

B

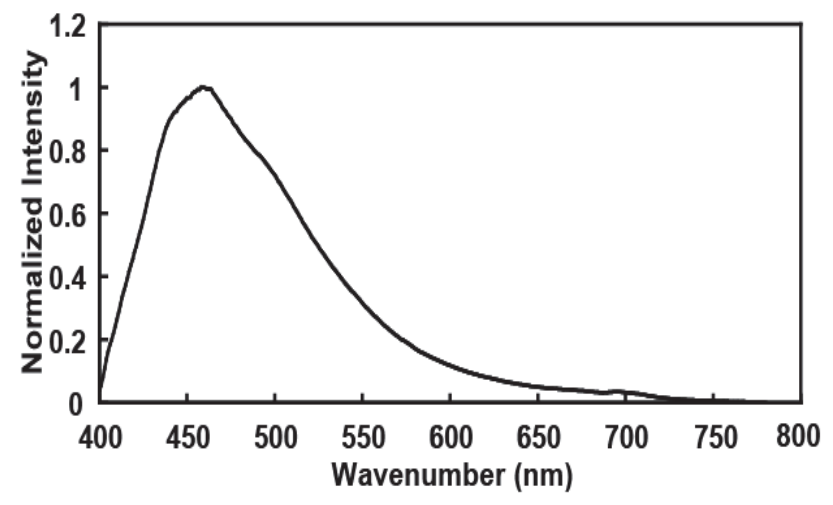

Fig. 5. Comparison of fluorescence spectra with excitation at $365 \mathrm{~nm}$. A, A normalized fluorescence spectrum of a colonic mucosal cross-section for this patient. B, A normalized fluorescence spectrum of a colonic mucosal cross-section in a classic case, shown for comparison. The fluorescence spectra (> $400 \mathrm{~nm}$ ) (E400LP v2; Chroma Technology Corp.) excited at $365 \mathrm{~nm}$ (D365/10x; Chroma Technology Corp.) were analyzed by using the multichannel spectrophotometer. 


\section{Discussion}

The autofluorescence intensity of a neoplastic lesion becomes attenuated under blue light excitation as a mucosal lesion progresses from normal status to early malignant disease, and this difference can be exploited to detect early neoplastic disease in the gastrointestinal tract (Huang et al., 2004; Haringsma et al., 2001). It is reported that the main source of tissue fluorescence is submucosal collagen and that the autofluorescence of the mucosal layer is weak in human, although the mucosal layer is the important source of autofluorescence in rat colons (Izuishi et al., 1999; Huang et al., 2004; Nakano et al., 2008; Nakano et al., in press). The attenuated autofluorescence in neoplastic lesions has been believed to be caused by a decrease in submucosal collagen-fluorescence due to the masking effect of mucosal thickening by neoplastic cells. In our patient, macrophages located in the luminal zone of the mucosal layer had stronger autofluorescence signals than the submucosal stroma. Therefore, the boundary of the tumor could be clearly recognized under AFI colonoscopy because of minimal scattering effect. DaCosta showed that macrophages in the lamina propria contribute to mucosal autofluorescence and suggested that lipofuscin granules in macrophages are fluorescent (DaCosta, 2000). In our case, however, the autofluorescence signal in macrophages was unusually strong and Schmorl reaction for lipofuscin and melanin was negative. We also performed fluorescence spectral and lifetime analyses, and Raman spectroscopic analyses (Nakano et al., in press; Harada et al., in press; Murayama et al., 2009; Harada et al., 2009; Ogawa et al., 2009), but it was not possible to identify the fluorophore in macrophages in our patient.

Abbreviations: WL, white light; AFI, autofluorescence imaging; DIC, differential interference contrast.

\section{Conclusion}

In conclusion, we report a rare case in which highly fluorescent mucosal macrophages were detected under AFI colonoscopy. The unusual cobblestone appearance of the intense mucosal autofluorescence in the non-neoplastic lesion markedly enhanced visualization of the tumor in comparison with more typical cases.

\section{Acknowledgment}

We thank staff of the Department of Gastroenterology and Hepatology, Kyoto Prefectural University of Medicine, for endoscopic examination, and Mrs. T. Okuda and T. Kawamura, Department of Pathology and Cell Regulation, for histological staining.

\section{References}

van den Broek, FJ.; Fockens, P.; van Eeden, S.; Reitsma, JB.; Hardwick, JC.; Stokkers, PC. \& Dekker, E. (2008). Endoscopic tri-modal imaging for surveillance in ulcerative colitis: randomised comparison of high-resolution endoscopy and autofluorescence imaging for neoplasia detection; and evaluation of narrow-band imaging for classification of lesions. Gut, Vol.57, No.8, (August 2008), pp. 1083-1089.

Matsuda, T.; Saito, Y.; Fu, KI.; Uraoka, T.; Kobayashi, N.; Nakajima, T.; Ikehara, H.; Mashimo, Y.; Shimoda, T.; Murakami, Y.; Parra-Blanco, A.; Fujimori, T. \& Saito, D. 
(2008) Does autofluorescence imaging videoendoscopy system improve the colonoscopic polyp detection rate?--a pilot study. Am J Gastroenterol, Vol.103, No.8, (August 2008), pp. 1926-1932.

Inoue, K ; Wakabayashi, N; Morimoto, Y; Miyawaki, K; Kashiwa, A; Yoshida, N;

Takada, H; Harada, Y; Yagi, N; Naito, Y; Takamatsu, T; \& Yoshikawa, T. (2010) Evaluation of autofluorescence colonoscopy for diagnosis of superficial colorectal neoplastic lesions. Int J Colorectal Dis, Vol.25, No.7, (July 2010), pp. 811-816.

Izuishi, K.; Tajiri, H.; Fujii, T.; Boku, N.; Ohtsu, A.; Ohnishi, T.; Ryu, M.; Kinoshita, T. \& Yoshida, S. (1999) The histological basis of detection of adenoma and cancer in the colon by autofluorescence endoscopic imaging. Endoscopy, Vol.31, No.7, (September 1999), pp. 511-516.

Huang, Z.; Zheng, W.; Xie, S.; Chen, R.; Zeng, H.; McLean, DI. \& Lui, H. (2004) Laserinduced autofluorescence microscopy of normal and tumor human colonic tissue. Int J Oncol, Vol.24, No.1, (January 2004), pp. 59-63.

Haringsma, J.; Tytgat, GN.; Yano, H.; Iishi, H.; Tatsuta, M.; Ogihara, T.; Watanabe, H.; Sato, N.; Marcon, N.; Wilson, BC. \& Cline, RW. (2001) Autofluorescence endoscopy: feasibility of detection of GI neoplasms unapparent to white light endoscopy with an evolving technology. Gastrointest Endosc, Vol.53, No.6, (May 2001), pp. 642-650.

Nakano, K; Harada, Y; Yamaoka, Y; Miyawaki, K; Wakabayashi, N; Mitsufuji, S; Imaizumi, K; Takaoka, H; Nakaoka, M; \& Takamatsu, T. Mucosal layer as major source of green autofluorescence in the colon under excitation by blue light. (2008) Progress in Biomedical Optics and Imaging - Proceedings of SPIE, Vol. 6853, Article number $68531 \mathrm{H}$.

Nakano, K.; Harada, Y.; Yamaoka, Y.; Miyawaki, K.; Imaizumi, K.; Takaoka, H.; Nakaoka, M.; Wakabayashi, N.; Yoshikawa, T. \& Takamatsu, T. Precise analysis of the autofluorescence characteristics of rat colon under UVA and violet light excitation. Curr Pharm Biotechnol, in press.

DaCosta, RS. (2000). Mechanisms of fluorescence endoscopy of the human colon. MSc Thesis MSc Thesis, Department of Medical Biophysics, University of Toronto, Ontario, Canada.

Harada, Y. \& Takamatsu T. Raman molecular imaging of cells and tissues: towards functional diagnostic imaging without labeling. Curr Pharm Biotechnol, in press.

Murayama, Y; Harada, Y; Imaizumi, K; Dai, P; Nakano, K; Okamoto, K; Otsuji, E. \& Takamatsu T. Precise detection of lymph node metastases in mouse rectal cancer by using 5-aminolevulinic acid. (2009) Int J Cancer, Vol.125, No.10, (Nov 2009), pp. 2256-2263.

Harada, Y; Dai, P; Yamaoka, Y; Ogawa, M; Tanaka, H; Nosaka, K; Akaji, K. \& Takamatsu, T. Intracellular dynamics of topoisomerase I inhibitor, CPT-11, by slit-scanning confocal Raman microscopy. (2009) Histochem Cell Biol, Vol.132, No.1, (July 2009), pp. 39-46.

Ogawa, M; Harada, Y; Yamaoka, Y; Fujita, K; Yaku, H. \& Takamatsu, T. Label-free biochemical imaging of heart tissue with high-speed spontaneous Raman microscopy. (2009) Biochem Biophys Res Commun, 2009 Vol.382, No.2, (May 2009), pp. 370-374. 


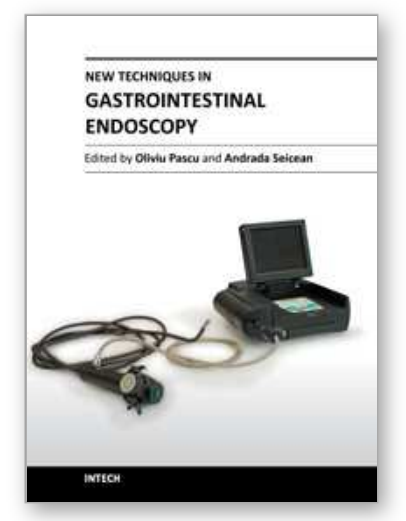

\author{
New Techniques in Gastrointestinal Endoscopy \\ Edited by Prof. Oliviu Pascu
}

ISBN 978-953-307-777-2

Hard cover, 310 pages

Publisher InTech

Published online 30, September, 2011

Published in print edition September, 2011

As result of progress, endoscopy has became more complex, using more sophisticated devices and has claimed a special form. In this moment, the gastroenterologist performing endoscopy has to be an expert in macroscopic view of the lesions in the gut, with good skills for using standard endoscopes, with good experience in ultrasound (for performing endoscopic ultrasound), with pathology experience for confocal examination. It is compulsory to get experience and to have patience and attention for the follow-up of thousands of images transmitted during capsule endoscopy or to have knowledge in physics necessary for autofluorescence imaging endoscopy. Therefore, the idea of an endoscopist has changed. Examinations mentioned need a special formation, a superior level of instruction, accessible to those who have already gained enough experience in basic diagnostic endoscopy. This is the reason for what these new issues of endoscopy are presented in this book of New techniques in Gastrointestinal Endoscopy.

\title{
How to reference
}

In order to correctly reference this scholarly work, feel free to copy and paste the following:

Tetsuro Takamatsu, Yoshinori Harada, Naoki Wakabayashi, Katsuichi Imaizumi, Kiichiro Miyawaki, Keimei Nakano, Yoshihisa Yamaoka, Akio Yanagisawa and Toshikazu Yoshikawa (2011). Highly Fluorescent Macrophages in Colonic Mucosa Under Autofluorescence Imaging Endoscopy: A Brief Case Report, New Techniques in Gastrointestinal Endoscopy, Prof. Oliviu Pascu (Ed.), ISBN: 978-953-307-777-2, InTech, Available from: http://www.intechopen.com/books/new-techniques-in-gastrointestinal-endoscopy/highlyfluorescent-macrophages-in-colonic-mucosa-under-autofluorescence-imaging-endoscopy-a-brief-ca

\section{INTECH}

open science | open minds

\author{
InTech Europe \\ University Campus STeP Ri \\ Slavka Krautzeka 83/A \\ 51000 Rijeka, Croatia \\ Phone: +385 (51) 770447 \\ Fax: +385 (51) 686166 \\ www.intechopen.com
}

\author{
InTech China \\ Unit 405, Office Block, Hotel Equatorial Shanghai \\ No.65, Yan An Road (West), Shanghai, 200040, China \\ 中国上海市延安西路65号上海国际贵都大饭店办公楼405单元 \\ Phone: $+86-21-62489820$ \\ Fax: $+86-21-62489821$
}


(C) 2011 The Author(s). Licensee IntechOpen. This chapter is distributed under the terms of the Creative Commons Attribution-NonCommercialShareAlike-3.0 License, which permits use, distribution and reproduction for non-commercial purposes, provided the original is properly cited and derivative works building on this content are distributed under the same license. 